\title{
Lack of data mires Aranesp in controversy
}

Citing patients' needs and unhappy with the US Food and Drug Administration placing a black box warning on Aranesp, as well as a government reimbursement decision that could threaten nearly $\$ 1$ billion of the drug's sales, Amgen has ratcheted up its lobbying in Washington. But without solid data on safe hemoglobin levels to lead the way out of the controversy, is Amgen's bullish strategy correct?

The FDA warning, added in March, urged that erythropoiesis-stimulating agents (ESAs) such as Aranesp (darbepoetin alfa), as well as Amgen's Epogen (epoetin alfa) and Johnson \& Johnson's Procrit (epoetin alfa), be used in the lowest dose possible that would still help patients avoid blood transfusions. Aranesp sales, which reached $\$ 4.1$ billion in 2006, fell 19\% in the US in the second quarter and $36 \%$ in the third. In July, the Center for Medicare and Medicaid Services (CMS) announced a new policy that would dramatically curtail its payments for all ESAs, saying it will reimburse for the drugs only when a cancer patient's blood hemoglobin falls below ten grams per deciliter-and stop paying when hemoglobin again rises above ten. The July 30 enactment of that policy by Medicare will hit hard: Amgen says Medicare paid for $\$ 945$ million of its global sales in 2006 (Table 1; Nat. Biotechnol. 25, 607-608, 2007).

The CMS decision raised a storm of protest from both Amgen and Johnson \& Johnsonwhose subsidiary, Ortho Biotech, of Bridgewater, New Jersey, sells Procrit. The companies were joined by prominent groups of blood and cancer doctors and the healthcare services network US Oncology in protesting that CMS was setting an arbitrary treatment standard without supportive evidence. (Insurer Aetna, of Hartford, Conneticut, followed CMS by saying in October it would restrict its payments for ESAs, too.)

Amgen also got busy on Capitol Hill. The Thousand Oaks, California-based firm doubled its spending on lobbying, with $\$ 9.1$ million in outlays in the first six months of 2007-almost as much as it spent in all of 2006. It dispatched lobbyists to meet with top aides to Department of Health and Human Services secretary Mike Levitt to persuade him that the ruling is bad. (He didn't budge, according to an unnamed source quoted in The Los Angeles Times.) It wooed House Speaker Nancy Pelosi at its headquarters. And it has, in face-to-face meetings and numerous conference calls, bent the ears of the Medicare officials who made the decision.

All that work appeared to have paid off. Following the CMS ruling, this summer both the House and Senate voted their "sense" that

\begin{tabular}{|ccc|}
\hline Table 1 Aranesp sales & \\
$\begin{array}{c}\text { Global sales } \\
\text { Year }\end{array}$ & $\begin{array}{c}\text { U } \text { U million) } \\
\text { (\$ million) }\end{array}$ \\
\hline 2004 & 2,473 & 1,533 \\
2005 & 3,273 & 2,104 \\
2006 & 4,121 & 2,790 \\
$20071^{\text {st }}$ & 1,020 & 654 \\
quarter & 949 & 578 \\
$2^{\text {nd }}$ quarter & 918 & 460 \\
$3^{\text {rd }}$ quarter & 818 &
\end{tabular}

the ruling should be reversed. Then in late September, two lawmakers with strong industry ties went a step further, introducing a resolution that would apply a rarely used Congressional power to overturn the CMS ruling. (The bill's sponsors, Anna Eshoo (D-Cal.) and Mike Rogers (R-Mich.), each collected close to $\$ 200,000$ from the drug industry and doctors' groups in the most recent election cycle.)

Amgen believes "many serious concerns raised by the oncology community" simply got the attention of "some of the US representatives," says Josh Ofman, Amgen's vice president of global reimbursement and payment policy. "It's important symbolically because there has been such a negative reaction to what CMS has done."

CMS responded to the noise. In a September 24 missive, referred to by agency insiders as the "put up or shut up" letter, it said the case is closed unless complainants present new evidence or prove that Medicare distorted existing data. CMS provided a list of questions it said needed answering, including: "What is the evidence that cancer patients undergoing chemotherapy require hemoglobin levels above ten?"

That question lies at the heart of the controversy, because evidence is lacking all around.

Kathleen Buto, the vice president for health policy at Johnson \& Johnson, who previously spent 18 years as a senior health policy official at the Medicare agency, says CMS is "essentially shifting the burden to the sponsor, asking us to prove that there is no harm [between ten and twelve] even when they don't have evidence that there is harm." And Paul Goldberg, editor of the Cancer Letter, pointed to a dearth of controlled data in that critical range-between 10 and 12 grams per deciliter. “One side says ' 10 ,' the other says ' 12 .' It's anything but inspiring to watch," he says. "Most of it is based on opinion. Hard data-by which I mean randomized clinical trials_-are nowhere to be seen."

Ajay Singh, a nephrologist at Brigham and Women's Hospital in Boston, who headed a large
2006 trial that showed a significantly increased risk of cardiovascular events and death in kidney patients treated until their hemoglobin levels were 13.5 grams per deciliter compared to patients treated to hemoglobin levels of 11.3 $\mathrm{g} / \mathrm{dl}$, agrees that more research is needed. "We need to find out whether it's the hemoglobin level or the drug itself that's associated with this increased risk of mortality, cardiovascular disease and, in cancer patients, increased tumor progression," he says.

Some openly question Amgen's lobbying. Merrill Goozner, the director of the Integrity in Science Project at the Center for Science in the Public Interest, a Washington, DC, advocacy group, says the issue "is the trials. They have trials showing that this stuff is harmful at high hemoglobin levels. Why are they pushing it?"

Democrat Pete Stark, the longtime Bay Area congressman who as head of the health subcommittee of the House Ways and Means Committee has authority over Medicare, also doubts the motives of Amgen and others. Before a closed meeting on October 4 of Stark's subcommittee, called to give Barry Straube, CMS's chief medical officer, a private platform to explain his decision to lawmakers, Stark publicly bemoaned the "lobbying frenzy and misinformation campaign" launched by Amgen and its allies. "A word of caution to my friends who act in the interest of corporate profits, not patient safety," he said, "thou doth protest too much."

Amgen begs to differ. "We are not in any way putting corporate greed over patient safety," says Amgen's Ofman, adding that the company has "done everything we can to communicate risks and benefits." He says that Amgen wants "physicians and their patients to decide how to use drugs," and that the company feels "very strongly that if the government is going to intervene in that process, it has to be science-based and evidence-based and not arbitrary."

Other analysts suggest that CMS is simply using the safety issue as an excuse to find savings on the costliest drugs in its medicine cabinet: Hard data are not yet available for 2006, but this year CMS expects to spend $\$ 5.4$ billion on Amgen and J\&J's anemia drugs, with about \$2.2 billion of that in patients with kidney disease and $\$ 1.6$ billion in patients with cancer. (Other anemia uses make up the remainder.)

"Restricting utilization is probably a good thing because you know it was overutilized," says Bill Tanner, an analyst who follows Amgen for Leerink Swann. "But then to couch what is really an economic argument as a safety concern is a little bit disingenuous."

Meredith Wadman, Washington, DC 